\title{
NO PUEDO SUJETAR LA PLUMA DE PURO FRÍO, PORQUE SON EXTREMADOS LOS YELOS: EL CLIMA EN LA ESPAÑA DE LOS REINADOS DE FELIPE V Y FERNANDO VI A TRAVÉS DE LA CORRESPONDENCIA DE ALGUNOS ILUSTRADOS*
}

\author{
Armando Alberola Romá \\ Universidad de Alicante
}

\section{RESUMEN}

El género epistolar encierra innumerables posibilidades investigadoras. En el presente estudio se analiza la correspondencia mantenida por cualificados representantes de la Ilustración española, prestando especial atención a las referencias de carácter climático que contienen los centenares de cartas cruzadas entre ellos. Se intenta con ello contribuir a una mejor caracterización del clima durante la primera mitad del siglo XVIII, a la vez que se apunta como hipótesis el potencial que puede tener esta fuente para posteriores trabajos.

Palabras clave: Ilustración, epistolarios, clima, percepción, sequía, lluvias, inundaciones, calor, frío.

\begin{abstract}
Epistolary genre encloses innumerable possibilities for research. In this paper, it is analyzed the correspondence supported by qualified representatives of Spanish Illustration, giving special attention to the references of climatic character that contain the hundreds of letters crossed between them. It is tried by it to contribute to a better characterization of climatic conditions during the first half of the XVIII ${ }^{\text {th }}$ century, simultaneously that signs as hypothesis the potential that this source(fountain) can offer for research works.
\end{abstract}

Key words: Illustration, epistolarios, climate, perception, drought, rains, floods, heat, cold.

Este trabajo ha sido elaborado en el marco del proyecto de investigación Riesgo y desastre natural en la España del siglo XVIII. Episodios meteorológicos extremos y sus efectos a través de la documentación oficial, la religiosidad popular y la reflexión científica (HAR2009-11928), que cuenta con financiación del Gobierno de España y Fondos FEDER. 


\section{El temple del tiempo en las cartas}

Vaya por delante que el presente estudio tiene pretensiones modestas, pues no supone más que una primera y muy somera aproximación a las sensaciones que dejaron anotadas algunas conocidas personalidades de la España del siglo XVIII sobre el clima que disfrutaron o padecieron. Indagando entre la abundante y variada documentación de primera mano que nos proporciona información sobre los episodios meteorológicos de diferente rango que se dejaron sentir durante la centuria ilustrada en el solar hispano ${ }^{1}$ hay una fuente enormemente interesante y poco explotada hasta la fecha dadas sus características formales. Me refiero a la correspondencia. No es éste lugar para reflexionar con amplitud acerca de la importancia que las relaciones epistolares adquirieron en la época que nos ocupa pues la sola referencia, por pequeña que fuera, a la personalidad de sus protagonistas precisaría de un espacio del que no dispongo ${ }^{2}$. Antonio Mestre ya se encargó de poner de relieve con acierto la significación que la carta llegó a adquirir, ya fuera desde el punto de vista intelectual, social, literario, político o, simplemente, como instrumento de comunicación utilizado por individuos unidos por lazos de la más variada índole (MESTRE, 2000). Precisamente la exhumación sistemática y el análisis exhaustivo de la ingente correspondencia que Gregorio Mayans mantuvo a lo largo de su vida con los representantes más cualificados de la Ilustración europea y española han permitido al profesor Mestre, a lo largo de más de cuatro decenios, establecer con precisión las complejidades que encerraba el siglo XVIII en su vertiente cultural, política y religiosa ${ }^{3}$. La historiografía reciente ha demostrado que el análisis del contenido de la correspondencia de diferentes ilustrados nos permite trazar con detalle la trayectoria vital y profesional de sus protagonistas - en el peor de los casos, al menos, hilvanar retazos - , conocer su círculo de relaciones, acceder a los arcanos de su entorno más personal, ser testigos privilegiados de sus logros y aspiraciones, de sus sensaciones y reacciones...; en fin, aproximarnos a su esfera más íntima.

En este contexto, y pese a que todavía me encuentro en la fase inicial de recopilación de datos, puedo adelantar que las informaciones relativas al «tiempo» y al impacto de diferentes meteoros, deslizadas entre párrafo y párrafo por quienes cultivaron con asiduidad la relación epistolar durante el siglo XVIII, ofrecen un interés que va más allá de la mera glosa al objeto central de la misiva, que siempre resulta ser otro. Y eso que los comentarios al respecto no dejan de ser, por lo común, muy parcos; aunque no por ello menos reveladores de una realidad que sus protagonistas se ven en la necesidad de trasmitir dado el carácter singular que para ellos adquiere. De ahí que los fríos excesivamente intensos o prolongados, una sequía persistente, los calores bochornosos de un verano tórrido, los vientos huracanados, los temporales, las heladas y pedriscos, las precipitaciones torrenciales, las riadas e inundaciones sean objeto de referencia en las cartas, viniendo a confirmar lo extraordinario de este tipo de acontecimientos meteorológicos y, sobre todo, el impacto que causaban en la sociedad del momento.

1 Referencias climáticas las podemos encontrar en innumerables fuentes documentales tal y como han puesto de relieve BARRIENDOS, 1999 o ALBEROLA, 2009.

2 Acerca de la importancia y significación de la carta como fuente histórica ver, por ejemplo, el número monográfico titulado Epistolarios. Correspondencia, que la Revista de Historia Moderna dedicó a la cuestión en su número 18 (Alicante, 2000).

3 A día de hoy Antonio Mestre ha dado a la imprenta, bien como autor principal, en colaboración o instando a terceros, un impresionante corpus de 24 volúmenes que contienen la fértil correspondencia mantenida por Gregorio Mayans a lo largo de su vida con los más cualificados corresponsales del siglo ilustrado a los que cabe añadir otros 37 de diferente formato sobre las múltiples facetas de la actividad intelectual del ilustrado de Oliva. 
En cualquier caso, el «hablar - o escribir - del tiempo» no deja de ser un elemento más de sociabilidad que no se puede perder de vista, y en el siglo XVIII la meteorología pasó a ser uno más de los temas objeto de comentarios y discusión en tertulias y sociedades científicas, adquiriendo poco a poco una mayor dimensión pública cuando los periódicos comenzaron a dedicar espacio en sus páginas a los resultados de las observaciones efectuadas y a las reflexiones relativas al «talante»o «temple» del tiempo y a sus hipotéticos efectos sobre la salud de las personas (ORLOVE y STRAUSS, 2003). Aparte de que introducir en conversaciones y escritos alusiones al tiempo atmosférico no deja de ser un socorrido tópico que hunde sus raíces en la noche de los tiempos (MARTÍ ESCAYOL, 2009). Tampoco conviene olvidar que el clima condicionaba sobremanera las actividades humanas, fueran del tipo que fueran. En este sentido, las inclemencias meteorológicas podían retrasar o impedir el normal funcionamiento del correo y quebrar el ritmo de una relación que exigía, precisamente, una cadencia estable tal y como sucedió con la mantenida entre el magistrado Blas Jover y el erudito Gregorio Mayans. Asimismo, y como también tendremos ocasión de comprobar, las tareas desarrolladas por intelectuales o técnicos para reconocer el territorio, buscar ruinas y vestigios históricos o, simplemente viajar por la geografía española, obligaban a trazar con precisión y método los planes a seguir. Sirva de ejemplo lo que exponía a mediados de siglo el literato malagueño Luis José Velázquez, futuro marqués de Valdeflores, a Agustín Montiano, director de la Academia de la Historia, en lo tocante al periplo que llevó a cabo por tierras castellanas, extremeñas y andaluzas para recopilar noticias con las que escribir una Historia de España:

«Esto [dibujar inscripciones y monumentos] lo he dexado para el fin de mi viaje (...) i para lo rigoroso del calor; aprovechando este tiempo de primavera en correr lo que me queda, porque en entrando el frío es imposible (...). El método que sigo en todos mis viajes es este: lo crudo del invierno y lo ardiente del verano debajo de techado, coordinando mis observaciones i recogiendo otras; i la primavera i el otoño a viajar» ${ }^{4}$

Hasta que se generalizaron y adquirieron la necesaria solvencia las observaciones científicas de carácter instrumental con utilización de termómetro y barómetro ${ }^{5}$, las referencias de carácter climático ya fueran «oficiales», es decir, procedentes de instituciones que amparaban estas tareas con fines científicos y utilitaristas, o las de carácter más privado que llevaban a cabo interesados en la cuestión, habitualmente médicos, tenían mucho que ver con las percepciones personales de cada observador. La frase que da título a este trabajo constituye una buena muestra de ello. Aparece intercalada en la misiva que remitió desde Madrid el presbítero y bibliotecario real Manuel Martínez Pingarrón a Gregorio Mayans el 9 de diciembre de 1752. El objeto de la misma - unos papeles o mapas que eran las láminas de la obra de Dn. Jorge Juan, entre otros comentarios-, era bien distinto al de la noticia climática que proporcionaba pero encierra un evidente interés por transmitir con prontitud unas circunstancias que, en esos instantes, incidían muy seriamente en el vivir cotidiano (MAYANS, 1987, 413). A la vez, pone de relieve la crudeza de ese invierno madrileño similar, por otra parte, a la de muchos otros a lo largo de la centuria, pues aunque durante

4 Biblioteca Nacional (BN), Manuscrito 17.546, Epistolario Luis José Velázquez-Agustín de Montiano. Velázquez a Montiano, Córdoba, 11-4-1754, f.167v.

5 Éstas se iniciaron en Madrid con notoria modestia de medios en la década de los treinta de la centuria auspiciadas por la Academia de Medicina Matritense tras aceptarse el plan propuesto por el médico granadino Francisco Fernández Navarrete, cf. en RICO SINOBAS, 1858. 
ésta se inició el tránsito hacia unas condiciones climáticas algo más suaves, la conocida como Pequeña Edad de Hielo continuaba en plena vigencia durante el siglo XVIII.

Para elaborar el presente trabajo he optado por limitar su amplitud cronológica hasta la llegada de Carlos III a España y utilizar, de manera aleatoria, los epistolarios que me resultaban más accesibles. Como quiera que Gregorio Mayans mantuvo correspondencia con numerosos y cualificados corresponsales, he prospectado aquéllos que podían ofrecer un mayor número de datos para el período. A tal efecto, han resultados fundamentales los correspondientes a Manuel Martí - y de éste con Felipe Bolifón -, Manuel Martínez Pingarrón y Blas Jover; aunque también he recogido noticias puntuales contenidas en la relación del erudito olivense con Antonio Bordazar, Andrés Marcos Burriel, José Borrull y Manuel Villafañe. A ellos he añadido el interesante y prolijo epistolario de Luis José Velázquez con Agustín Montiano y algunas cartas dirigidas por el naturalista Pehr Löfling a su maestro Carl Linné(o) así como otras del profesor de Artillería de la Academia de Guardias Marinas, José Díaz Infante, al erudito José Carbonel. Un análisis minucioso y concienzudo de los numerosos epistolarios de que, a día de hoy, disponemos, podría depararnos información muy jugosa; quizá del estilo de la proporcionada, con los excelentes resultados que conocemos, por el Calaix de Sastre del barón de Maldá (BARRIENDOS, 2009). Aunque esto está aún por ver y lo apunto como mera hipótesis.

\section{De fríos crueles y calores tartáreos}

Durante el siglo ilustrado fueron especialmente severos en España los inviernos de 17081709 y 1716 (KAMEN, 1974; LE ROY LADURIE, 1991 y 2004; FONT TULLOT, 1988, 71-94). El primero de ellos, con la guerra de Sucesión dejando sentir sus terribles secuelas, resultó espantoso para todo el continente europeo. Así lo destaca el conde de Buffon en su Historia natural cuando señala, en el análisis demográfico que efectúa, la reducción en una quinta parte de los nacimientos en ese año y el incremento, hasta duplicarlas, de las defunciones (BUFFON, 1797, VI, 188). Vicente Bacallar de Sanna, marqués de San Felipe, contemporáneo de los hechos y participante en el conflicto desde el bando felipista, refiere en sus Comentarios a la guerra de España que

«no tenían los mortales memoria de tal exceso de frío como el de este año; heláronse muchos ríos tan vecinos al mar que formaba margen el hielo; secáronse por lo intenso de él los árboles. (...). No corría líquida el agua, ni la que se traía en las manos para beber (...). Morían los centinelas en las garitas y no hallaba casi reparo la humana industria contra tan irregular inclemencia, no hicieron progreso los sembrados, y se introdujo el hambre en los países más fríos» ${ }^{6}$.

Conocedor con toda probabilidad de esta obra, el padre Feijoo tacha este invierno como el más cruel de los conocidos en los párrafos postreros de la segunda de sus Cartas eruditas y curiosas (FEIJOO, 1786, I, 48). Venía a ser continuación de uno no menos extremado que había expirado con la misma destemplanza (SAN FELIPE, 1957), y sus consecuencias resultaron dramáticas: el mar Báltico permaneció helado durante buena parte de la estación, las nevadas fueron muy abundantes en Inglaterra, la agricultura padeció sobremanera en Francia tras aniquilar el frío muchas especies arbóreas y, según Rico Sinobas, se heló el Mediterráneo en Marsella y Génova (RICO, 1851, 40). En España, el río Ebro se congeló a su paso por Tortosa, para los sevillanos constituyó un invierno de los que jamás se habían

6 BACALLAR DE SANNA, V., marqués de San Felipe, 1957, p. 167. 
conocido y en Alicante no les quedó otra opción a los defensores ingleses de su castillo, sitiado por las tropas borbónicas y último bastión austracista del reino valenciano hasta la primavera de 1709, mas que abandonar reiteradamente la protección de las murallas con el fin de conseguir leña con la que paliar el frío y poder cocinar (TULLOT, 1988, 95 y 99; MALTÉS y LÓPEZ, 1752). Respecto de este último episodio, don Juan José Navarro, primer marqués de la Victoria, integrante del contingente partidario de Felipe de Anjou y participante en la construcción de la mina que hizo volar parte de la fortaleza alicantina, señala en sus Memorias, utilizadas por José Vargas Ponce para elaborar la biografía del ilustre militar, que en el sitio de Alicante pasó un invierno que ha dexado perpetua memoria por su intemperie y dureza ${ }^{7}$.

Las inclemencias invernales depararon una muy menguada cosecha en todo el continente, propiciando la primera de las grandes crisis que padecería Europa durante la centuria. En la península Ibérica, a la dureza del invierno sucedió una primavera muy lluviosa que colapsó las comunicaciones, provocó graves inundaciones, caso de Sevilla, y, en general, malogró las cosechas en curso, con lo que durante el año 1709 el hambre se erigió en siniestra protagonista en Murcia, La Mancha y Extremadura (KAMEN, 1974, 392 y 421-422).

Entre 1711 y 1713 la Meseta Norte padeció una sequía notable. En 1718 los fuertes calores del verano anunciaban la irrupción de una fase más cálida y suave aunque los inviernos continuaran siendo muy crudos, como el de 1718-1719 que fue especialmente frío en Andalucía donde se malogró la producción de aceitunas. No obstante, el intenso calor y la sequedad del estío, prolongados más allá de los meses otoñales, ocasionarían funestas consecuencias en muchas regiones del país al arruinar buena parte de sus producciones agrícolas; lo cual contribuiría a disparar los precios, fundamentalmente del grano. Especial gravedad revistió la sequía que desde el otoño de 1718 afectó durante siete cosechas consecutivas a las comarcas agrícolas próximas a la zona de los Monegros, y que halló su correlato en tierras levantinas durante los años veinte y treinta. Le Roy Ladurie no dudó en calificar los veranos de 1717 y 1718 como los más cálidos y secos del siglo XVIII pese a constatar, asimismo, el avance experimentado por los glaciares en el norte y centro de Europa entre 1716 y 1719 , a tenor de la gran cantidad de procesiones y rogativas que se sucedieron para solicitar del Altísimo su retroceso; lo cual viene a mostrar la pervivencia de la fase fría y húmeda aludida y su coexistencia con períodos de intenso calor (LE ROY LADURIE, 1991, 80, 260-261). Estas circunstancias extremas se dejarían sentir con mayor intensidad durante el último cuarto de la centuria, sobre todo en el Mediterráneo occidental.

De todos modos, calores estivales y sequía no eran óbice para que las lluvias descargaran de manera extemporánea, se produjeran heladas y granizos o los inviernos se manifestaran en ocasiones extremados. En este sentido, en la dilatada y fértil correspondencia mantenida durante el invierno de 1720 y la primavera de 1737 entre el humanista Manuel Martí, deán que fue de la iglesia colegial de San Nicolás de Alicante, y el ilustrado Gregorio Mayans ${ }^{8}$ encontramos referencias - no muchas, es cierto - a alguno de estos acontecimientos (MAYANS, 1973; MESTRE, 2003). Pero hay que tener presente que, en este contexto en el que la percepción sensorial juega un papel fundamental, se tiende a comunicar aquello que se sale de lo habitual o que adquiere categoría de extraordinario. Lo normal no suele ser noticia. De ahí, entiendo, el valor que encierran los comentarios de quienes mantienen estrecha y constante relación epistolar.

Por lo que hace a la sequía que estuvo presente durante la década de los veinte en la práctica totalidad de las regiones españolas resulta significativa la información que,

7 VARGAS PONCE, 1808, p. 14.

8 Sobre Mayans resultan imprescindibles las obras de MESTRE, 1968, 1970, 1999. 
a primeros de septiembre de 1722, José Borrull trasladaba desde Salamanca a Gregorio Mayans acerca de los vaivenes climáticos de la Meseta norte. Comentaba que, tras el fuerte estío soportado y combatido gracias a que la nieve - adquirida a un precio muy razonable - no les faltó durante el verano ni a él ni a su familia, el tiempo comenzaba a cambiar según el estilo del país con unos calores interpolados que obligaban bien a hechar ropa fuera, ya de armarnos con ella para resistir al imponente Aquilo. Para colmo de males, los efectos de la gran sequedad padecida se habían visto incrementados con los de una epidemia de virguelas (sic) que se cobraba ocho muertos por día (MAYANS, 1996, 314).

A primeros de septiembre de 1723 comentaba el deán Martí a su corresponsal el mal verano que había padecido como consecuencia de los fuertes calores. Acostumbraba aquél a desplazarse desde Alicante a la finca conocida como «del Pobil», propiedad del deanato y situada en la cercana huerta, donde se respiraba un ambiente más fresco que en la ciudad; pero por esas fechas se estaba concluyendo la capilla de la comunión de la colegial de San Nicolás, obra que llevaba a cabo el reconocido arquitecto y escultor Juan Bautista Borja (SÁEZ VIDAL, 1985). La supervisión de éstas fue, probablemente, la razón que retuvo a Manuel Martí ese verano en Alicante intra muros, por dependencias gravísimas de la Iglesia en donde son los calores tartáreos, y el contraste entre las altas temperaturas externas que lo empapaban de sudor y el ambiente más bien fresco del interior del templo fue la causa de un enfriamiento que derivó en fuerte catarro que le importunó durante tres semanas. Ello le hizo sufrir en carne propia los rigores caniculares que castigaban con dureza por esas fechas el Levante peninsular y que causaron graves estragos en las producciones agrícolas de la huerta; daños de los que el deán daría cumplida noticia, con posterioridad, en diferentes informes elevados al Ayuntamiento alicantino.

En contrapartida, el 21 de enero de 1729 confesaba su sorpresa a Mayans ante la inusual severidad de la estación, y reconocía que de ser acérrimo partidario del invierno se había convertido en decidido detractor del mismo:

«Han sido tan crueles (y son) los fríos de este invierno que sin embargo de ser yo $\varphi \imath \lambda \circ \chi \varepsilon \ddot{\mu} \mu \omega v$ he pasado al estremo contrario de $\mu 1 \sigma o \chi \varepsilon \ddot{\mu} \mu \omega v$. Mi thermómetro ha baxado a los 34 grados. Cosa inaudita en este clima. Y assí ha tres semanas que me levanto a las 9 y me acuesto a las tres de la tarde. Reparos necessarios contra tan poderoso enemigo: sin tener acción aun para santiguarse»9 .

El año anterior, por esas mismas fechas, Manuel Martí había comunicado al napolitano Felipe Bolifón, administrador de rentas en la ciudad de Alicante entre 1709 y 1725 (GIMÉNEZ, 1981), hombre culto y refinado con quien congenió y mantuvo relación epistolar cuando éste hubo de trasladarse temporalmente a Madrid, un raro episodio de intensas precipitaciones invernales que había ocasionado la formación de una laguna en las inmediaciones de la ciudad. Insistía el deán en que el vaso de la misma no se había visto aumentado por algunas avenidas de las aguas, sino por las lluvias de invierno que allí afluyen, no ocultando su preocupación por el problema sanitario que podría entrañar tan pronto irrumpieran los calores veraniegos provocando su putrefacción y la aparición de las conocidas - y sufridas - fiebres tercianas (MARTÍ, 1979, 105; ALBEROLA, 1985; ALBEROLA y BERNABÉ, 1998-1999).

9 MAYANS, 1973, 192-193. El frío de Martí estaba justificado pues los 34 grados que arrojaba su termómetro Fahrenheit equivalían a $1,1^{\circ}$ de la escala Celsius. 
La sensación que Manuel Martí tuvo de la dureza del invierno aludido, inhabitual por demás en la urbe alicantina donde la templanza de sus temperaturas era lo normal, encaja a la perfección con la situación atmosférica general de esos momentos. Hay datos que señalan que los inviernos de 1726-1727 y 1728-1729 resultaron gélidos, precisamente en el ámbito mediterráneo, donde abundaron las nevadas (FONT TULLOT, 1988, 99). Una década más tarde las circunstancias se repetirían en todo el continente, siendo conocido como el «gran invierno europeo» el correspondiente a 1739-1740, que dejaría sentir sus severos efectos en el norte peninsular, donde el río Pisuerga llegó a estar tan profundamente helado durante toda la segunda quincena del mes de enero de 1739 que entraron las gentes y se pasearon como pudieron por el campo (RICO SINOBAS, 1851, 41-42). No menos severos resultaron los de 1744-1745, 1754-1755 así como el anormalmente frío verano padecido en 1750 en el noroeste peninsular. Al respecto, Le Roy Ladurie incluye el período comprendido entre este último año y 1752 en uno de los tres grupos de años especialmente fríos, tras analizar y concordar series fenológicas francesas y curvas termométricas inglesas (LE ROY LADURIE, 1991, 86).

Respecto a las fases de sequía anteriormente aludidas, cabe señalar que las de tipo general y larga duración no fueron frecuentes, con la excepción del período 1749-1753; mientras que las de carácter local resultaron ser pertinaces contrastando, en múltiples ocasiones, la prolongada ausencia de agua con violentas precipitaciones de alta intensidad horaria seguidas de las consabidas avenidas e inundaciones (FONT TULLOT, 1988, 101). Para la primera mitad de la centuria hay documentadas lluvias torrenciales, de carácter local aunque de tremendos efectos, en Madrid (1723), Segovia (1725) y en toda la Meseta norte, que afectaron seriamente a la agricultura motivando la celebración de rogativas pro serenitate en Zamora y otras poblaciones (FONT TULLOT, 1988, 101-102). Especial repercusión alcanzó la furiosa tempestad que el 15 de septiembre de 1723 descargó sobre Madrid provocando una furiosa riada del Manzanares que sorprendió a relevantes miembros de la nobleza en la casa de campo del duque de la Mirándola celebrando su cumpleaños. Perecieron ahogados María Teresa Spinola de la Cerda, esposa del anfitrión, Francisco Pío de Saboya y Moura, marqués de Castel Rodrigo, y el por entonces capitán general de Guipúzcoa Tiberio Caraffa. El suceso apareció reflejado en las páginas de la Gazeta de Madrid, de la London Gazette así como en las memorias del duque de SaintSimon y quedaría grabada en la memoria histórica hasta el punto de que sería utilizada por Manuel Martínez Pingarrón como elemento de comparación para valorar un suceso de similares características - tempestad fuertíssima, con un aguacero tan grande i piedra, que ha causado muchos daños - acaecido a finales de septiembre de 1775 (GIMÉNEZ, 2001; ALBEROLA, 2005; ABASCAL, DIE y CEBRIÁN, 2009; SAINT-SIMON, 19831988). Otro ejemplo más de los contrastes que podían tener lugar lo ofrece la ciudad de Orihuela que, pese a la continua sequía que padeció durante este período la comarca del Bajo Segura, no escapó a las inundaciones del río del mismo nombre que, sistemática e irremediablemente, se presentaban en los meses otoñales provocando que las rogativas encaminadas a aplacar los temporales de lluvia se convirtieran en un elemento más del paisaje urbano (ALBEROLA, 2006).

No dispongo por ahora de demasiadas referencias procedentes de epistolarios que abunden en esta cuestión y que aporten opiniones más «personales» de aquellos aspectos que ya conocemos en profundidad y desde diferentes ópticas, gracias al análisis de fuentes de carácter «oficial». No obstante, alguna hay para la década de los treinta surgida de pluma cualificada. Así el impresor valenciano Antonio Bordazar refería a Gregorio Mayans el 19 de septiembre de 1731 los terribles efectos ocasionados en Valencia y municipios aledaños, tres días atrás, por una imponente riada del Turia. La capacidad de síntesis es 
evidente, en el más puro estilo epistolar, así como la convicción del impresor de que la mano de la divina providencia andaba detrás del desastre:

«Aquí huvo una inundación del Turia el día 16 a las dos de la tarde, cual no se ha visto desde el año 1517, pues llegó el agua hasta cerca de la piedra que Vm. avrá visto a un estado en la puerta del convento de la Trinidad. Salió por el llano de la Zaidía, calles de Murviedro, Alboraya, Alameda, el Remedio, etc. dentro de la ciudad redundó por los albañales en toda la plaza de santo Domingo, Temple, Blanquería, en donde vi echarse a nado a recoger pieles i otras cosas. En Cuarte, Manises, Alacuás i otros lugares se llevó muchos ganados i muebles; i singularmente en Alacuás derribó la mayor parte de las casas; personas no se dice que ayan perecido más que de cinco a seis, pero el daño en casas, árboles, vituallas i muebles, se juzga de 300 mil ducados. Dios nos perdone i nos dé consuelo i conformidad en sus altíssimas disposiciones» ${ }^{10}$.

Esta riada, considerada como una de las más destructivas padecidas por la capital del viejo reino valenciano hasta ese momento, fue convenientemente recogida por contemporáneos y cronistas como el padre Teixidó o el archivero Pahoner (PÉREZ y FAUS, 1990; ALBEROLA, 1999, 60-61). Bordazar daría a la imprenta, al poco de producirse el acontecimiento, un folleto de ocho páginas titulado Puntual relación de la Avenida de el Río Turia en el que relataría con mayor amplitud el desastre (BORDAZAR, 1731), aunque haría notar sin recato alguno al propio Mayans en carta fechada el día 26 de ese mismo mes de septiembre que, para ello, se había inspirado en el contenido del Verdadero Resumen y compendioso diseño de la memorable avenida de el Turia, un romance que, al respecto, compuso Pascual Vergadá tal y como recogió Faus Prieto (MAYANS, 1993, 66; FAUS PRIETO, 1988, 20). El jurista Blas Jover, en misiva remitida a Mayans desde Valencia el 25 de septiembre, no hacía sino corroborar estos extremos:

«No siendo fácil explicar el conflicto en que nos puso la inundación, ni los daños que a ocasionado remito a $\mathrm{Vm}$. por ganar tiempo que para todo falta, esos dos romanzotes que groseramente quentan lo que aquí pasó» ${ }^{11}$.

Pese a estos excesos hídricos, la sequía no dejó de proyectar su larga sombra durante este período propiciando la constante celebración de rogativas y procesiones ad petendam pluviam. Hasta que el siglo alcanzara su ecuador es destacable la persistencia del fenómeno en diferentes ámbitos de la geografía española: Castilla y Levante (1720-1724), Aragón y Levante (1725), ambas Castillas y Andalucía (1738, 1739), los Monegros y buena parte del país (1748-1755) o la Meseta y Levante (1757) (FONT TULLOT, 1988, 101). Al respecto, de nuevo la correspondencia entre Manuel Martí y Gregorio Mayans ofrece referencias significativas. A finales de abril de 1733, el deán de Alicante se disculpaba ante su corresponsal por haber tardado demasiado en dar respuesta a una misiva fechada el día 14 de ese mes. Comentaba que se hallaba desesperado (...) por estar sin vista, ni tener de quien valerme y justificaba su retraso en el hecho de que su coadjutor, que era quien le llevaba la pluma, se encontraba embargado en la solemne ocupación de traer la Verónica o Santa Faz en rogativa de agua (MAYANS, 1973, 285-289). Y es que desde el año 1725 , y a la vista de la extrema esterilidad que padecían los campos alicantinos por la

10 MAYANS, 1993, 65-66.

11 MAYANS, 1991, p. 68. 
acusada falta de precipitaciones, se había acordado transformar en públicas las rogativas que hasta ese momento se desarrollaban en secreto. En septiembre de ese año 1733 las cosas habían cambiado poco. Martí, que a la sazón se encontraba en la finca de la huerta alicantina donde solía pasar el verano, comentaba a Mayans cuánto deseaba que el tiempo refrescara para poder leer y escribir con comodidad, quejándose de la sofocante canícula y de que los calores son mayores hoy [18 de septiembre] de lo que han sido en el mes de agosto (MAYANS, 1973, 317-318). Y es que la sequía siempre constituyó, y constituye, el principal problema de una sociedad eminentemente agraria.

Al respecto, Blas Jover proporciona quince años más tarde detalles muy interesantes acerca de la situación general del país, manifestando su preocupación por los graves inconvenientes que podía provocar la conjunción de una adversa meteorología con la feroz langosta azotando los campos manchegos, castellanos y extremeños. La sequía era general en todo el reino, sobre haber sido corta la sementera, y en el reino de Murcia ninguna; el hambre era extrema en Mallorca e Ibiza y comenzaba a amenazar a Cataluña; las enfermedades eran muchas y agudas, como lo eran igualmente las diferencias entre los gobernantes a la hora de diseñar las medidas más eficaces para afrontar el problema. Jover concluía su reflexión de manera muy sombría apelando a Dios para que pusiera su mano con estos males pues, de lo contrario, habrá mucho que temer en este año (MAYANS, 1991, p. 241).

Hay muchas otras informaciones de procedencia epistolar que abundan en estos mismos asuntos y es probable que, poco a poco y con las cautelas siempre necesarias, podamos llegar a configurar un corpus que nos permita efectuar una aproximación fiable a las condiciones climáticas de las décadas cuarta y quinta del siglo ilustrado. Calor abrasador en verano, prolongada sequía y frío invernal convivieron con intensas precitaciones equinocciales durante los años cuarenta. Tiempos difíciles, presagio de otros peores.

Desde Utiel, Manuel Martínez Pingarrón transmitía a Gregorio Mayans a fines de 1739 que tenía noticias de que en la Corte sucedían muchas desgracias por el mal temporal. El 27 de enero de 1740 comentaba, ya desde Valencia, que iba a permanecer en la ciudad del Turia por tiempo indeterminado porque los caminos estaban peligrosos e impracticables; y a mediados de marzo se confesaba sitiado por el tiempo que, después de las nieves, se ha cargado tanto de agua que ni aun salir de casa permite. Hasta el 30 de abril no arribaría a la Corte libre ya, a Dios gracias, de aguas, malos caminos y restablecido a mi salud (MAYANS, 1987; 99, 100, 102, 103). Los calores de los veranos inmediatos fueron abrumadores, los precios de la carne de vaca y carnero experimentaron un alza y, a primeros de octubre de 1741, transmitía Pingarrón informes procedentes de Asturias que alertaban de que la sequía proseguía tras más de diez meses sin caer una gota de agua, habiendo comenzado a morir personas y animales. En su despedida, el bibliotecario se encomendaba a la piedad y gran misericordia divinas, pues es bien menester (MAYANS, 1987, 152-153, 159). Ya en vísperas de las navidades de 1742 refería que Madrid se veía azotado por un temporal rigurosísimo de yelos, nieves y ahora aguas (MAYANS, 1987, 192).

Las abundantes y precisas noticias que jalonan la correspondencia que mantuvieron Blas Jover y Manuel Martínez Pingarrón con Gregorio Mayans permiten reputar como especialmente inclementes el otoño e invierno de 1745. El primero escribía que en octubre se padecía en Madrid un tiempo cruel [que], naturalmente será general por todas partes, con abundantes lluvias que se prolongaron durante todo noviembre e impidieron el normal funcionamiento del correo entre Valencia y la Corte. En navidad las cosas fueron a peor, permitiendo a Jover establecer una comparación con sus vivencias diplomáticas suizas al comentarle a Mayans que el rigor del tiempo que se experimenta [es] tan frío y 
nebuloso como en los Alpes, por lo qual ha llegado tardísimo el correo ${ }^{12}$. La proximidad de la primavera no traería la ansiada mejora; y si a primeros de marzo de 1746 el tiempo en Madrid se había puesto furioso de aguas y nieves con fríos inmensos y más sensibles que en el norte retrasando sobremanera la llegada de los correos, en Oliva no iba la cosa mejor pues, en su respuesta, Mayans decía estar padeciendo un frío tan terrible que no le he tenido igual en estos parages (MAYANS, 1991, pp. 304, 306).

Estos temporales se harían habituales a medida que el siglo se encaminaba hacia su ecuador y, aparte del malestar, incomodidades y desgracias que provocaban, retrasaban sobremanera los correos al verse afectadas muy seriamente las comunicaciones. Ésta es una queja reflejada con frecuencia en la correspondencia pues, además de lo dicho, distorsionaba no poco las relaciones mantenidas por nuestros ilustrados. Así, mientras Jover se debate a primeros de abril de 1746 en la duda de si llegará o no el correo, estando el tiempo de lluvias sin cesar, el jesuita Burriel tan pronto se lamenta ante Mayans de que con los aguaceros el correo no suele llegar a tiempo - 4 de diciembre de 1745-, o siente infinito el atraso de la de Vmd. de 9 de enero que recibí de mano de un cartero el martes de esta semana -21 de enero de $1747-$. Aunque finalmente reconoce $-\mathrm{y}$ justifica, iqué remedio! - la demora porque el tiempo ha estado cargadísimo de lluvias y nieves. Mal «tiempo» pues en la Corte y aledaños, generalizable asimismo a buena parte de la porción occidental del país, a tenor de los comentarios que, tras llegar a León procedente de Extremadura y Salamanca, deslizaba Manuel Villafañe a Gregorio Mayans a primeros de ese mismo mes de enero ${ }^{13}$. Concluyendo la década, Martínez Pingarrón alude a los inviernos desabridos de 1747 y 1748, empleando expresiones como sumos yelos o la crueldad del tiempo, a la vez que muestra su preocupación por las consecuencias del terremoto de Montesa que sacudió los corregimientos centrales valencianos en las postrimerías de marzo de 1748 (MAYANS, 1987, 312-313; ALBEROLA, 1999, 79-173). El magistrado Blas Jover, por su parte, corroboraba a primeros de marzo de 1748 las palabras del bibliotecario real, al afirmar que la nieve alcanzaba una vara de altura en Madrid (MAYANS, 1991, p. 68), a la vez que mostraba idéntica preocupación en abril por los efectos calamitosos ocasionados por el terremoto de Montesa.

\section{Habrá un año malísimo: sequía, crisis y enfermedad}

Los años cincuenta del siglo XVIII depararon a España oscilaciones atmosféricas relevantes que provocaron serios contratiempos en la producción agrícola (ANES, 1970; PÉREZ MOREDA, 1980), un tanto desigualmente reflejados en la documentación de carácter más oficial, pero que han dejado rastro en la correspondencia que cruzaron diferentes ilustrados. Para el estudio de esta secuencia temporal proporcionan abundante información los epistolarios del marqués de Valdeflores con Agustín Montiano y el de Gregorio Mayans con el magistrado Blas Jover. Ambos se complementan a la perfección con los que vengo reseñando hasta el momento - sobre todo con el del presbítero y bibliotecario real Manuel Martínez Pingarrón - y se caracterizan por abarcar la década central de la centuria y ofrecer la siempre conveniente amplitud geográfica.

La correspondencia mantenida entre el literato malagueño Luis José Velázquez y Agustín Montiano, director por entonces de la Real Academia de la Historia, a cuenta del viaje que

12 Jover a Mayans, Madrid, cartas fechadas el 16 de octubre, 13 y 27 de noviembre y 25 de diciembre de 1745; cf. en MAYANS, 1991, pp. 250, 270, 275 y 285.

13 «Desde Salamanca aquí me trabajaron igualmente densas i penetrantes nieblas que desde Extremadura hasta aquella ciudad, añadiéndose a la adversidad del temporal la mala constitución de los caminos infestados de pícaros»; Villafañe a Mayans, León, 6-1-1747 (MAYANS, 1996, 448). 
el primero realizó comisionado por esta institución por Extremadura y Andalucía con el objeto de recoger inscripciones y catalogar monumentos antiguos con los que elaborar una Historia General de España, ofrece numerosos datos para el período comprendido entre las postrimerías del mes de diciembre de 1752 y las de noviembre de $1755^{14}$. Lamentablemente, esa Historia que tantos desvelos y fatigas procuró a Valdeflores jamás vio la luz, debiéndose contentar éste con la publicación en 1765 de un mero apunte de su pesquisa titulado Noticia del Viaje de España (ABASCAL, DIE, CEBRIÁN, 2009, 32-34). Pero el relato de los avatares de su periplo está cuajado de noticias de carácter climático transmitidas con un lenguaje sencillo y directo, propio del que está viviendo en carne propia el azote de una meteorología implacable.

La relación epistolar de Blas Jover con Gregorio Mayans se alargó desde el verano de 1730 hasta la primavera de 1754, con una breve interrupción motivada por la coincidencia de ambos en Madrid entre marzo de 1738 y septiembre de 1739 y la forzosa ausencia de España del primero desplazado en la primavera de 1742 a la legación helvética de Lucerna. Las posiciones regalistas de ambos, los conflictos con el Papado a cuenta del Concordato y los informes que, en esta línea, elaboraban Gregorio y Juan Antonio Mayans para quien, desde febrero de 1744, era fiscal de la Cámara de Castilla con competencias en las regalías de la Corona propiciaron un contacto intenso en el que, con una cadencia semanal salvo imprevistos, son bastante habituales los comentarios que intercambian relativos al comportamiento del «tiempo». Da la impresión de que ambos corresponsales gustaran de reservar siempre unas líneas para comentar el temple de la atmósfera en sus respectivos lugares de residencia.

La quinta década del siglo ilustrado se inició con la sequía castigando la práctica totalidad del país. Desde su Oliva natal, Gregorio Mayans hacía notar a Blas Jover a primeros de julio de 1750 la alarmante carencia de trigo que se observaba en Valencia así como el alza inexorable de su precio, lo cual le hacía augurar lo peor de no mediar remedios drásticos, como el recurso al grano ultramarino:

«Si con tiempo no se da providencia para que venga trigo a España habrá un año malísimo. Ya tengo el que he menester (que son veinte caíses) a nueve libras el caís salido de las eras, precio que en esta villa años ha que no se ha visto tan subido» ${ }^{15}$.

La respuesta de Blas Jover, una semana más tarde, no hacía sino confirmar el alcance del desastre, pues desde la Corte aludía a la gran esterilidad que padecían los quatro reinos de Andalucia. Ello había hecho acelerar la autorización para importar trigo y hacerlo circular con prontitud aunque existiera un grave problema de liquidez ya que se carecía de lo mejor, que es el dinero para comprarlo ${ }^{16}$. Agosto resultó ser un mes extraño, con tormentas ocasionales y pedriscos que contribuyeron a refrescar momentáneamente el ambiente, tanto en Madrid como en Valencia, aunque los calores siguieron apretando - aquí nos quemamos de calor, escribía Jover el 29 de agosto - hasta el otoño acompañando a la tremenda sequía que, en la Corte, amenazaba con suspender el suministro de agua para el consumo humano. Casi por las mismas fechas Martínez Pingarrón comunicaba el desplazamiento hacia Andalucía del corregidor de Madrid, comisionado por la Corona y portador de una fuerte cantidad de dinero, para

14 Biblioteca Nacional (BN), Manuscrito 17.546, Epistolario Luis José Velázquez-Agustín de Montiano.

15 Mayans a Jover, Oliva, 4-7-1750; cf. MAYANS, 1995, p. 328. Sobre las crisis de subsistencia en Valencia ver PALOP, 1977a y 1977b; ALBEROLA, 1999.

16 Jover a Mayans; Madrid, 11-7-1750; cf. MAYANS, 1995, p. 330. 
«remediar aquel país i hacer revivan los labradores, dándoles granos, ganado, etc. i que también coma todo el país. Dicen que el millón de pesos es para empezar i que se le irá embiando más, según él avise de la necesidad» ${ }^{17}$.

La situación general se antojaba delicada, las rogativas pro pluvia puestas en marcha a mediados de octubre no habían surtido efecto alguno y la despedida de Jover a Mayans en una de sus cartas destilaba un fuerte tufo providencialista: Dios nos mire con ojos de misericordia. El erudito de Oliva, por su parte y en clara sintonía, le respondía el 31 de octubre: aquí nos ha dado Dios, por su misericordia, agua bastante» ${ }^{18}$. De todos modos la lluvia no volvería a irrumpir en tierras valencianas hasta enero pese a los numerosos días nublados, mientras que en el interior castellano proliferaron las tormentas durante todo noviembre provocando inundaciones, destrozos, fiebres y los consabidos retrasos en el correo. Decía Jover en sucesivas cartas:

«En éste [país] también tenemos una gran constelación de tercianas, porque nos a llovido a dilubiar tres semanas, y saliendo de madre ríos y barrancos han hecho muchos estragos. (...). A la de Vm. de 13 de este mes no respondí por lo turbados que [han] andado los correos a causa de la inundación general de la carrera, que an motibado quarenta días de llubias continuas» ${ }^{19}$.

En términos muy similares se expresaba Martínez Pingarrón, aunque incluía también a la nieve en una especie de memorial de quejas climáticas. De ahí que el invierno de 1750-1751 quepa considerarlo frío y lluvioso en el interior y con anómalas bonanzas térmicas en la costa que, por su brevedad, no hacían sino desconcertar a quienes las vivían. Al respecto, es muy expresivo el comentario que Gregorio Mayans hacía el 6 de febrero de 1751, quejándose de que en Oliva habían pasado repentinamente del calor al frío, i no hace tiempo sino de estar junto a una chimenea. A primeros de mayo concluía el erudito que la atmósfera se comportaba de manera «irregular», ya que hacía el frío que dejó de hacer en el invierno. Pocos días más tarde se ratificaba en su opinión pues, sin solución de continuidad, comenzaba ya a explicarse el calor con molestia. Notables contrastes en muy poco tiempo, que se confirmaban en Madrid y en otros lugares. Jover comentaba el 22 de mayo que, frente a los calores olivenses, en la capital del reino experimentaban un frío como en enero; aunque siete días más tarde la situación había variado radicalmente al tener de tres días a esta parte un calor como por julio, no dudando en calificar el «tiempo» de crítico y variable (MAYANS, 1995, pp. 357-368).

El verano de 1751 fue muy caluroso y huérfano de agua, y los pocos chaparrones del otoño apenas contribuyeron a «templar los calores». La cosecha fue mala en Valencia, y aunque a finales de septiembre llovió algo no resultó suficiente. Mayans temía un alza desmesurada de los precios de los productos agrícolas pues por entonces la fanega de cebada comenzaba a pagarse a 15 ó 16 reales. Por su parte, Jover dibujaba idéntico panorama desde Madrid el 9 de octubre: había llovido poco, no lo bastante para sembrar y sí para hacer un frío intolerable; y aunque ello no impedía que la familia real y su corte marcharan hacia El Escorial el magistrado pronosticaba que no permanecerá tanto tiempo como en otros años. A tenor del contenido de una misiva posterior, Jover erró en su apreciación pues, tras las lluvias de mediados de octubre, volvió un calor demasia-

17 Martínez Pingarrón a Mayans, Madrid, 22-8-1750; cf. MAYANS, 1987, pp. 344-346.

18 La correspondencia mantenida por ambos durante agosto y septiembre en MAYANS, 1995, pp. 333-344.

19 Ibídem, pp. 344-345. 
damente fuerte de día y de noche fresco, porque se nos ha entrado el veranillo de San Martín (MAYANS, 1995, 373). En noviembre, sin embargo, todo cambió bruscamente. Las precipitaciones fueron persistentes, abundantes y destructoras. Martínez Pingarrón no cesa de repetir en sus cartas los constantes retrasos que sufren los correos en su tránsito por tierras manchegas como consecuencia de los temporales y los persistentes chubascos que azotan Madrid. A modo de anécdota comenta al ilustrado olivense haber sufrido un grave enfriamiento que le obligó a guardar cama tras la mucha agua que cogí yendo a la rogativa mientras relata, de manera muy gráfica, que las aguas son tantas que las calles parecen ríos $i$ no se puede salir de casa (MAYANS, 1987, pp. 381-382). Por su parte, Mayans advertía desde Oliva a primeros de ese mes que se decían cosas espantosas de los ríos y torrentes valencianos mientras las nubes, lejos de levantar, se mostraban amenazantes en el cielo. Por su parte Jover, al responderle, no ahorraba detalles para referir la situación en Madrid y alrededores:

«Si Vm. han tenido aí aguas, inundaciones y cosas espantosas, aquí ha sido igualmente el temporal, sólo con la diferencia de que teniendo determinado S.M. restituirse a esta villa el sávado 13, no lo pudo conseguir hasta el domingo en la tarde con bastante penalidad, por lo qual estamos todavía amargados de maiores trabajos, si Dios no nos remedia» (MAYANS, 1995, 376).

Ese invierno resultó lluvioso y frío, entorpeciendo sobremanera la actividad de los correos. Jover comentaba a comienzos de febrero que la semana anterior no había llegado la posta, y que en la presente llegaba tan tarde y moxado, que apenas da lugar para abrir las cartas. Mayans, desde Oliva, suspiraba en marzo de ese año 1752 porque el tiempo cambiara de una vez porque no he visto año como este; deseo que passe el invierno, para que los aires sean más benignos (MAYANS, 1995, 383 y 391). Sin embargo la primavera fue inclemente y destemplada, con lluvias, escaso calor e irrupción de enfermedades. Hasta mediados de julio el tiempo fue muy frío e irregular, con el paludismo - endémico visitante estival de las tierras deprimidas y encharcadas del antiguo reino valenciano - dejándose sentir en buena parte del territorio peninsular y adquiriendo la dimensión de una auténtica epidemia. Jover y Mayans sufrieron sus efectos tal y como refieren en varias cartas. El primero en propia carne; el segundo en la de varios miembros de su familia ${ }^{20}$. Y con la sequía bien presente y amenazante.

En el otoño de 1752, gracias a Dios, hubo lluvias importantes en el centro del país que aconsejaron al padre Andrés Marcos Burriel, por entonces en Toledo, retrasar la remisión a su hermano de un paquete con noticias y extractos procedentes de códices antiguos $^{21}$. A las precipitaciones otoñales siguió un invierno especialmente gélido y destemplado. Desde la Corte, el bibliotecario real Manuel Martínez Pingarrón se lo hacía saber al polígrafo olivense a principios del mes de diciembre de un modo muy gráfico: no puedo sujetar la pluma de puro frío, porque son extremados los yelos, sin aver forma de que llueva ni nieve (MAYANS, 1987, 413). Similar sensación transmitía Velázquez de Velasco a Montiano el día 28 de ese mismo mes desde Mérida, adonde había llegado procedente de Madrid para cubrir un itinerario que había de conducirle al poco - con alguna incursión en tierras castellanas - hacia Andalucía. Anotaba el literato malagueño

20 Las cartas cruzadas entre el 21 de octubre y el 2 de diciembre aluden a la cuestión, proporcionando noticias de los efectos de la enfermedad, las fases de mejoría y de la «reparación» de los enfermos; MAYANS, 1995, pp. 408-410.

21 Andrés Marcos Burriel a Pedro Burriel, Toledo, 24-10-1752; en SALVÁ y SÁIZ, 1848, p. 233. 
que por acá no hay más novedad, sino el mucho frío que ha hecho estos días procedido de unos terribles aires; situación que, a más de mantenerse durante enero, sospechaba podía complicarse en los meses venideros pues se arrastraba una ausencia demasiado prolongada de precipitaciones ${ }^{22}$.

A comienzos de 1753 el presbítero Pingarrón se lamentaba de que el tiempo se siguiera comportando con crueldad en Madrid, mientras que Gregorio Mayans refería a Jover que, en Valencia, pese a que el invierno había entrado blandamente, ahora se explica con rigor. Éste, a su vez, se mostraba preocupado en marzo por la ausencia de pasto y la mortandad del ganado aunque confiaba en que la cosecha fuera buena, pues se había endulzado el tiempo tras padecer furiosos fríos y yelos intolerables en los meses invernales. La preocupación estaba justificada: tan pronto la Corte partió hacia Aranjuez a finales de abril los precios se dispararon y comenzó a dejarse sentir un cierto desabastecimiento. El comentario al respecto de Martínez Pingarrón es bien elocuente para poder valorar la situación:

«La Corte se fue el miércoles a Aranjuez i al instante nos han subido la carne tres quartos la libra; la comemos a 16 quartos la libra de carnero i a 15 la de baca; ya sabe Vmd. que la libra aquí es de 16 onzas. Huebos no se hallan, el tocino está mui caro i assí de lo demás. El pan se ha subido un quarto; le comemos a 8 quartos el pan de dos libras» ${ }^{23}$.

La primavera resultó muy seca y hubo constantes rogativas en demanda de agua en tres santuarios y sin dejar en su lugar a las santas imágenes, mientras escaseaba el pan y su precio continuaba subiendo ${ }^{24}$. Pese a las lluvias que descargaron en Madrid durante junio suavizando las temperaturas, ese verano fue de nuevo seco y muy caluroso. El presagio de Valdeflores referido a Extremadura aludido líneas atrás se cumplió y los comentarios que, en este sentido y mezclados con otros directamente relacionados con su tarea, fue recibiendo el director de la Academia de la Historia dibujan un escenario preocupante durante los meses de primavera y verano. En efecto, las cartas remitidas entre el 26 de abril y el 18 de junio de 1753 no dejan lugar a dudas: el territorio extremeño se hallaba padeciendo los efectos de una severa sequía, algo en absoluto extraño, pues el país que por su naturaleza es seco i cálido, lo es mucho más a causa de no haver llovido en el invierno añadiendo, a modo de estrambote, lo dura que se le hacía la tarea diaria pues $s i$ en alguna tierra no se puede trabajar por el verano es en Extremadura ${ }^{25}$. Pero no sólo allí; un desplazamiento hacia el norte visitando Brozas, Alcántara, Coria, Plasencia y Oliva que le condujo hasta Fuente Roble en las proximidades de Salamanca - donde no llegó a entrar-, permitió comprobar al literato malagueño la gravedad de la situación, con una acusada carencia de productos de primera necesidad que comenzaba a afectar seriamente a la población. Los comentarios al respecto son muy elocuentes cuando, en diferentes cartas, le indica a Agustín Montiano:

«El año por acá será malísimo, porque no lluebe, no hai que comer, i yo estoi reducido a mascar perdiz y mas perdiz, porque no hai otra caza, el pan es endemoniado y los caminos quaxados de ladrones (...). [Regresando desde Salamanca] El tiempo

22 BN. Manuscrito 17.546, Velázquez a Montiano, Mérida, 28-12-1752; f. 5. Velázquez a Montiano, Mérida, 27-1-1753; Ibídem, f. 14v.

23 Martínez Pingarrón a Mayans, Madrid, 28-4-1753; cf. MAYANS, 1987, p. 435.

24 Martínez Pingarrón a Mayans, cartas de 12 y 19 de mayo de 1753; MAYANS, 1987, Pp. 437-438.

25 BN. Manuscrito 17.546, Velázquez a Montiano, Mérida, 22-6-1753; f. 66. 
que va entrando en calor me insta a retirarme; y la infelicidad a que están reducidos estos pueblos me obligó a acelerar mi vuelta para aprovecharme de la ocasión del abasto de la cebada que en este camino hai prevenida para el Regimiento de Pavía, porque si no no pudiera dar un paso, porque no hai un grano en los pueblos y los caleseros no quieren andar por aquí por ese motivo» ${ }^{26}$.

Al frío y seco invierno había sucedido la sequía y, de vuelta hacia Mérida siguiendo la Ruta de la Plata y con el calor dejándose sentir sin piedad, Valdeflores no abrigaba duda alguna de que

«este año [1753] será aquí más cruel que otro, por la suma sequedad (...). Los pueblos están infelices y no se halla ni que comer, ni facilidad para transitar, faltando la paja y la cebada para las bestias. En este viaje me ha costado en muchas partes a 5 (?) Reales la fanega, y por aquí podrá V. conocer como estará todo lo demás» ${ }^{27}$.

Idéntico era el sentir del naturalista sueco Pehr Löfling, discípulo del famoso Carlos Linneo, que se hallaba en España desde finales de octubre de 1751 enviado por su maestro tras haber rechazado éste una oferta del gobierno de Fernando VI para trabajar y enseñar en España. La estancia de Löfling en la península se alargaría hasta 1754, en que pasaría a América formando parte, en calidad de botánico del Rey, de la expedición de límites que se dirigió a los llanos del Orinoco comandada por José Iturriaga y Eugenio de Alvarado (PELAYO, 1990; LUCENA, 1992). Hasta el momento de embarcar hacia el continente americano desde Cádiz, llevó a cabo diferentes tareas y mantuvo correspondencia con Linneo. En una de esas cartas, fechada en Madrid el 14 de mayo, coincidía plenamente con Velázquez en su valoración de la estación invernal - sorprendente, incluso, para quien, como él, venía del norte de Europa - y el estado en que se hallaba la agricultura como consecuencia del adverso comportamiento de la atmósfera:

«El invierno ha sido tan riguroso que no hay memoria de otro igual; de modo que nosotros extrañamos la benignidad de los inviernos del norte. (...) Aquí se experimenta una carestía tan grande que no hay memoria de otra igual. Se teme una escasez general, porque es considerable la mortandad del ganado. Los calores son tan excesivos y el verano tan rigoroso como el invierno. Dios me dé salud para resistir» ${ }^{28}$.

Las noticias remitidas por Gregorio Mayans a Blas Jover hablaban de un verano sofocante en la costa mediterránea, con riesgo de fuertes tercianas y la amenaza cierta de que no habría trigo suficiente de no mediar las providencias oportunas; providencias que, al decir de Blas Jover, estaban en marcha con el fin de que se pudiera pasar «mejor el invierno» aunque, lamentablemente, el precio del pan continuara alto (MAYANS, 1995, pp. 426-429).

En agosto de 1753 Luis José Velázquez tenía concluida la Relación de su viaje en la que describía con detalle cada provincia, población por población, incluyendo un mapa de Extremadura con el ánimo de escribir la Geografía moderna ${ }^{29}$, algo muy en la línea de

26 BN. Ibídem, Velázquez a Montiano, Mérida, 26-4-1753, f. 46v. Velázquez a Montiano, Baños [de Montemayor], 22-5-1753, f. 53.

27 BN. Ibídem, Velázquez a Montiano, Mérida, 28-5-1753, f. 54.

28 Pehr Löfling a Carl Linné, Madrid, 14-5-1753, Anales de Ciencias Naturales, mes de junio de 1802, $\mathrm{n}^{\mathrm{o}} 13$, tomo V, p. 92.

29 BN. Ibídem, Velázquez a Montiano, Mérida, 10-8-1753, ff. 82-83. 
lo que propugnaba el marqués de la Ensenada y que motivó que el científico Jorge Juan presentara un proyecto para levantar el mapa de España. Pese a sus deseos de abandonar Mérida para lograr una ciudad más fresca que esto o, a lo menos, que sea más divertida, permanecería en ella hasta comienzos del mes de septiembre sufriendo los calores del estío y la soledad. La urbe cacereña se le antojaba lo mismo que un desierto: ni gentes, ni paseos, ni cosa alguna. Por fin, tras tener listo el carruaje pertinente, el día 7 inició viaje hacia Granada adonde llegaría once días más tarde, observando una calzada antigua que desde Mérida sigue hasta Granada, dejando tras de sí un verano largo y abrasador que había ocasionado no pocos problemas de salud a él y a sus acompañantes ${ }^{30}$. Verano que se corresponde con el padecido en Madrid y Valencia por Jover y Mayans, quienes en sus cartas hacen referencias explícitas a calores «excesivos»e «intolerables» (MAYANS, 1995, pp. 425-426).

El viaje por la maior parte de los quatro reynos de Andalucia acopiando información y vestigios históricos ocuparía a Valdeflores, oficialmente y con financiación de la Academia de la Historia, hasta finales de 1754 aunque prolongaría a sus expensas la misión, ampliando incluso el ámbito de estudio a las posesiones españolas situadas en el norte de África, La Mancha y parte de Castilla la Nueva ${ }^{31}$. En su comunicación constante con Agustín Montiano sigue mostrándose en extremo detallista, aportando jugosos comentarios respecto del comportamiento de la atmósfera. Así, concluyendo el mes de octubre de 1753, refiere desde Granada que la sequía es persistente, dando cuenta de la recepción de una orden real para suspender la representación de comedias. Esta era una decisión habitual cuando se daban estas circunstancias adversas, pues las autoridades daban preferencia a la celebración de rezos, procesiones y rogativas hasta que la normalidad meteorológica retornara. Sin embargo, ello no obstaba para que en Granada

«Los cómicos y el pueblo están consternados; unos piensan que van a quitar las Comedias del todo; otros que paran por la sequedad del año. Dígame V. lo que allá se dice de esto i si hai algo de lo que se piensa ${ }^{32}$.

Ante una pregunta tan directamente formulada, Agustín Montiano respondió el 6 de noviembre de manera lacónica pero no por ello menos reveladora: Que estamos aquí en el mismo caso. En idénticos términos contestaba Jover a Mayans - experimentamos una gran sequedad y frío-, significándole el singular contraste con las abundantes precipitaciones que descargaban en Valencia las cuales, como era habitual, impidieron o retrasaron la llegada del correo desde la Corte. Sequía, pues, generalizada en una amplia porción del territorio peninsular de la monarquía hispánica durante el año 1753. Sequía que, al poco y al menos en Andalucía, cedería paso a las anheladas precipitaciones a partir de noviembre, mes en el que Velázquez hacía saber que por acá llueve muy bien, por lo que se espera un buen $a \tilde{n} o^{33}$. Estas lluvias descargarían durante todo ese invierno, en ocasiones ininterrumpidamente día y noche, coexistiendo con unos fríos que pocas vezes se han visto ${ }^{34}$; noticia relevante

30 BN. Ibídem, Velázquez a Montiano, Mérida, 6-9-1753, ff. 96-97; Velázquez a Montiano, Granada, 189-1753, f. 98; y 25-9-1753, f. 100 .

31 ABASCAL, DIE, CEBRIÁN, 2009, 34. El manuscrito del Viaje por una parte del reyno de Castilla la nueva, toda la Provincia de Extremadura, y parte del reyno de León hasta Salamanca, en Real Academia de la Historia (RAH) CAG-9-7980-5/42; cf. en MAIER (2002), igualmente CEBRIÁN, SALAMANQUÉS y SÁNCHEZ (2005).

32 BN. Ibídem, Velázquez a Montiano, Granada, 30-10-1753, f. 116v.

33 BN. Ibídem, Velázquez a Montiano, Granada, 6-11-1753, f. 117.

34 BN. Ibídem, Velázquez a Montiano, Granada, 1-1-1754, f. 137. 
si consideramos que la proporciona Velázquez desde Málaga el día primero de enero de 1754, y máxime cuando apenas una semana después vuelve sobre el asunto y lo aduce para justificar sus escasos movimientos:

«Si el tiempo no estuviera por acá tan crudo, ya hubiera yo salido para una viajata [sic] por estos contornos registrando las ruinas de Cartima, Munda, Arunda, Acinipo y otras. Espero a que el tiempo se temple y al punto saldré. (...) Entre tanto voy trabajando en los mapas modernos y en la geografía antigua de la Bética ${ }^{35}$.

Un invierno excesivamente riguroso éste de 1753-1754, con muchas lluvias, inhabitual en la costa mediterránea y generalizable al interior peninsular y a la Meseta a tenor de los datos que proporciona Martínez Pingarrón para los meses de diciembre a febrero. El retraso de la correspondencia por culpa de los temporales es comentario reiterado en sus misivas a Mayans; al igual que las alusiones a nevadas y al padecimiento de «fríos cruelissimos» (MAYANS, 1987, pp. 456-464). Velázquez, por su parte, al dar cuenta a Montiano a finales de enero de una viajata por Salobreña, Motril y otras poblaciones costeras, escribe que se vio muy apurado con el mal tiempo, de aires y fríos; respondiéndole su interlocutor a primeros de febrero que en Madrid también está recio el temporal ${ }^{36}$. Por esas mismas fechas anota igualmente que tras desplazarse a unas cinco leguas de Málaga, buscando unas ruinas, regresó a la ciudad maltrecho y helado, cubierto de nieve, lleno de frío, i molidas las espaldas de una caída que di del caballo; no obstante confiaba en que el tiempo se «serenara» para poder partir hacia Granada ${ }^{37}$. Ello no sucedió hasta los últimos días de febrero, cuando notificaba que en breve se pondría en marcha hacia Granada donde llegó el 12 de marzo anunciando a Montiano sus intenciones de dirigirse presto hacia Jaén, Linares, Porcuna y Martos hasta recalar en Córdoba. Justificaba esta planificación porque haviendo ya templado el tiempo voy a aprovecharlo ${ }^{38}$. Tras cumplir su itinerario, Velázquez comunicaba a su corresponsal a finales de mes su llegada a la ciudad califal. El invierno, a más de muy frío, resultó igualmente lluvioso prolongándose las precipitaciones hasta la entrada de la primavera para general contento, pues era «cosa que ya se deseaba mucho» ${ }^{39}$. Las lluvias se generalizaron a la práctica totalidad del país descargando con profusión a lo largo del mes de abril y, según anotaba Pingarrón, de toda España escriven que ha llovido, menos en Aragón que no ha sido cosa i especialmente en tierra de Huesca; gracias a Dios que nos ha consolado ${ }^{40}$.

De Córdoba, Velázquez encaminaría sus pasos hacia Sevilla para, desde allí, dirigirse a Cádiz vía Antequera. El 5 de mayo de 1754 se encontraba en el Puerto de Santa María entrando, al día siguiente, en la urbe gaditana cuyo bullicio y falta de sosiego le dejó aturdida la cabeza, deseando salir cuanto antes de ella para poder pensar ${ }^{41}$. Un mes después, el 4 de junio ya escribía desde Sevilla, aludiendo al fuerte bochorno que le había acompañado durante el viaje y, tras una incursión a Écija, informaba siete días más tarde que los recorridos a la búsqueda de vestigios los llevaba a cabo antes del amanecer (...), antes que entre lo fuerte del calor, porque entonces es imposible viajar ${ }^{42}$. El estío andaluz resultaba

\footnotetext{
35 BN. Ibídem, Velázquez a Montiano, Málaga, 8-1-1754, f. 139.

36 BN. Ibídem, Velázquez a Montiano, Málaga, 29-1-1754, f. 142.

37 BN. Ibídem, Velázquez a Montiano, Málaga, 5-2-1754, f. 148.

38 BN. Ibídem, Velázquez a Montiano, Granada, 12-3-1754, ff. 153-154.

39 BN. Ibídem, Velázquez a Montiano, Córdoba, 28-3-1754, f. 156v.

40 Martínez Pingarrón a Mayans, Madrid, 13-4-1754; MAYANS, 1987, p. 476.

41 BN. Manuscrito 17.546, Velázquez a Montiano, Cádiz, 14-5-1754, f. 176.

42 BN. Ibídem, Velázquez a Montiano, Sevilla, 11-6-1754, f. 180v.
} 
insoportable y la canícula sería compañera implacable en su caminata hacia Málaga, donde arribó el 25 de ese mismo mes bien molido i con bastante calor, porque el sol no se puede ya sufrir $^{43}$. Allí le sorprenderían las noticias de la caída del marqués de la Ensenada, su mentor, y recibiría las recomendaciones de Montiano de actuar con discreción en tanto se decidiera en Madrid si continuaba o no su comisión. No le vino mal durante julio, agosto y septiembre un poco de descanso en una estación tan rigorosa como aquí hace ${ }^{44}$. A mediados de noviembre la meteorología cambió radicalmente, cosa por otra parte habitual en la dinámica atmosférica de la estación, comenzando a descargar precipitaciones de manera abundante e insistente, reflejándolo de modo muy gráfico Velázquez al escribir que por acá ha más de 15 días que casi no cesa de llover; y las aguas han sido generales en toda Andalucía $a^{45}$. Desde Madrid, el bibliotecario Pingarrón abundaba en lo mismo quejándose, de nuevo, de las constantes interrupciones y retrasos que sufrían sus relaciones epistolares por las fuertes precipitaciones, presentes desde las postrimerías de octubre, y el comienzo de las nevadas el 30 de noviembre preludio de un invierno que resultó mui riguroso y en el que los precios de los productos básicos experimentaron subidas apreciables (MAYANS, 1987, 504-508, 517-518). Al respecto, resulta elocuente el comentario que desliza a Mayans el 8 de febrero de 1755 lamentando con amargura que no está el tiempo para comprar muchos libros, pues aier costaba cada huebo añejo 3 quartos, y a este respecto ba todo ${ }^{46}$. En la primera semana de marzo el bibliotecario real resumía perfectamente la situación que, pese a la crudeza invernal, intuía podía tornarse favorable aunque los precios no bajaran

Aquí va el tiempo preciosamente (aunque no por esto se abaratan las cosas) pues desde hoi hace ocho días casi no ha dejado de llover de día i de noche; i esto es que antes, a sus tiempos, llovió mucho, nevó mucho i heló muchíssimo. Por esto llegan los correos mui tarde, o mui atrasados, pues de algunos no se han recibido cartas hasta el lunes i creo que hoi suceda assíi ${ }^{47}$.

De todos modos, las postrimerías del invierno de 1755 resultaron en exceso desapacibles y frías, provocando los contratiempos habituales con el correo. En una extensa carta, el bibliotecario real deslizaba a Mayans estos comentarios que no hacían sino reiterar los anteriores

«Aquí ha vuelto a nevar i helar, como si empezasse el invierno, i se oyen muchas desgracias que han sucedido en los caminos por las muchas aguas i nieves. Veremos si llega el correo a tiempo de poder responder a la de Vmds. de hoy. (...) Amigo mío. Ya va anocheciendo i el correo [de Valencia] no ha venido, como ni el de Castilla, ni de otras partes» ${ }^{48}$.

En este contexto, el verano ofreció en sus comienzos lluvias abundantes y persistentes así como temperaturas anómalamente frías que transportaban a Martínez Pingarrón $a$ entradas del invierno ${ }^{49}$. Por su parte, Velázquez no vuelve a proporcionar en sus cartas referencia alguna al tiempo atmosférico en la costa mediterránea hasta finales del mes de

43 BN. Ibídem, Velázquez a Montiano, Málaga, 26-6-1754, f. 182.

44 BN. Ibídem, Velázquez a Montiano, Málaga, 30-7-1754, f. 190, y 6-8-1754, f. 193.

45 BN. Ibídem, Velázquez a Montiano, Málaga, 19-11-1754, f. 222.

46 Martínez Pingarrón a Mayans, Madrid, 8-2-1755; cf. MAYANS, 1987, pp. 518-519.

47 Ibídem, Madrid, 1-3-1755; cf. MAYANS, 1987, pp. 522-523.

48 Martínez Pingarrón a Mayans, Madrid, 15-3-1755, cf. MAYANS, 1987, p. 529.

49 Ibídem, Madrid, 7-6-1755; cf. MAYANS, 1987, pp. 540-541. 
julio de 1755; quizá porque no se produjeron incidentes llamativos. De ahí que, para el literato malagueño, el año agrícola se desarrollara con la anhelada normalidad, con unos precios en la zona asequibles en el grano y el pan, debido a la feracidad de esta tierra en años de abundancia ${ }^{50}$. Las últimas noticias que nos depara su correspondencia con Montiano hasta finales de ese año reflejan el impacto ocasionado por el terrible terremoto y posterior tsunami que el día 1 de noviembre destruyeron Lisboa, asolando las regiones meridionales portuguesas y causando terribles estragos en Andalucía occidental (MARTÍNEZ SOLARES, 2001). En Málaga y poblaciones vecinas los temblores se dejaron sentir a partir de las 10 de la mañana, por espacio de medio cuarto de hora sin parar, dejando los edificios mиy quebrantados, aunque sin ocasionar víctimas. Velázquez transmite las noticias que fueron llegando a Málaga y que describían el desastre vivido en Huelva y Cádiz, casi sumergidos Ayamonte y Tarifa, y con un número importante de víctimas. La sensación de tristeza, desorden y confusión ante el tremendo acontecimiento es palpable en las últimas cartas ${ }^{51}$. Martínez Pingarrón también da cuenta a Mayans del impacto causado en Madrid por el terremoto en sucesivas misivas remitidas desde el primer día de ese mes de noviembre hasta la conclusión del año, a la vez que informa de que el frío, con lluvias y nieve, comienza a apretar en la Corte ${ }^{52}$. Abundan los detalles sobre el comportamiento de las gentes, los daños padecidos en edificios e infraestructuras, la actuación de las autoridades para hacer frente a la situación, las informaciones de primera mano procedentes de la corte lisboeta, la aparición de relaciones impresas sobre lo sucedido en Ayamonte y Sevilla y una manuscrita referente a Lisboa - todas ellas enviadas a Mayans - , la puesta en marcha de una pesquisa general; en fin, el presbítero bibliotecario utilizó de toda su influencia para estar bien informado y hacer lo propio con su corresponsal olivense. Incluso da cuenta de las obras de reparación que fue necesario efectuar en su propia casa al haber quedado muy dañada por los temblores y con los cimientos al aire.

\section{Langosta, muchísimas aguas y fríos insoportables: Madrid está hecho una loncha de hielo}

Precisamente, retazos de la correspondencia mantenida entre ambos aportan referencias algo más fragmentarias para los restantes años de esta década. La primavera de 1756 resultó lluviosa y fría en la Corte, con lluvias y nieves en los puertos; pero también en Andalucía a tenor de la misiva que, desde Chiclana remitía a mediados de mayo el profesor de Artillería José Díaz Infante al erudito José Carbonel ${ }^{53}$. Sin embargo, sería la langosta la que se erigiría en siniestro protagonista del verano de 1756 y de los dos sucesivos, al desencadenar un terrible ataque que agostó los campos de buena parte del país. Las desgracias ocasionadas por la plaga ocupan abundante espacio en la correspondencia cruzada entre Gregorio Mayans y Manuel Martínez Pingarrón, pues el viejo reino valenciano las padeció sobremanera y Mayans, en su Oliva natal, fue testigo de excepción del modo de actuar de las densas nubes que componían los voraces ortópteros.

50 BN. Manuscrito 17.546, Velázquez a Montiano, Málaga, 22-7-1755, f. $263 \mathrm{v}$.

51 BN. Ibídem, Velázquez a Montiano, Málaga, 4-11-1755, f. 263v; 11-11-1755, f. 286; 18-11-1755, ff. 287-287v; 25-11-1755, f. 289.

52 Martínez Pingarrón a Mayans, cartas fechadas en Madrid los días 1, 8 y 15 de noviembre, así como las de los días 6 y 26 de diciembre de ese año 1755; cf. MAYANS, 1987, pp. 553-559.

53 «Por acá ay sus trabajos porq. los resfriados se cruzan y el tiempo crudo no nos permite sacar la caveza de nntro. domicilio; pero vamos pasando hasta que Dios quiera que nos veamos», BN. Mss. 11553, pp. 150b-150d, José Infante a José Carbonel, Chiclana, 17-5-1756. Sobre José Carbonel ver DIE, 2010. 
El invierno de 1756-1757, al decir de Pingarrón, fue terrible en la Corte pues le tuvo en continuo sobresalto por el tiempo cruelissimo de nieves y hielos después de muchíssimas aguas (...), con fríos insoportables (MAYANS, 1987, pp. 64 y 70). Mayans, por su parte, le respondía que en Oliva había nevado extraordinariamente y confiaba en que ello fuera una manifestación divina contra la langosta para evitar la ruina total de una población prisionera de

«una miseria general, porque los que no tienen que comer, ¿cómo han de pagar? Faltó la cosecha de la adaza, la del aceite i algarrovas, i hasta los irracionales no tienen que comer en estos parages donde la langosta hizo tanto mal» ${ }^{54}$.

La escasez se adueñó del territorio al perderse las cosechas, el tiempo no acompañaba, y el ilustrado valenciano resumía con precisión, y no poco fatalismo providencialista, el grave problema de desabastecimiento al que se enfrentaban en el verano de 1757:

«yo no puedo darlas [las noticias] sino melancólicas por las avenidas de la langosta, que han sido terribles, i han empezado a causar algún daño, que se teme mui grave si el viento no la arroja al mar. Hasta ahora ya la vemos con horror por su multitud, ya no la vemos porque el viento la trasporta, i si llega a detenerse tendremos peor año que el passado, que ha sido malíssimo. I en éste el trigo ha sido poco i no mui bueno, la adaza está atrasada, el aceite i las algarrobas pocas, i no sabemos qué sucederá a estas cosechas, las viñas en gran peligro i la gente atónita, las cobranzas malíssimas. I no ai más esperanza que la de Dios que todo puede convertirlo en bien, i lo convertirá» ${ }^{55}$.

En diciembre era un hecho que los responsables políticos de Oliva no podrían hacer frente a los compromisos fiscales de la villa y darían con sus huesos en prisión. Los daños de la langosta alcanzaban a todos y ni las lluvias otoñales ni el enfriamiento de la atmósfera que presagiaba la llegada del invierno hicieron mella en los insectos. Pingarrón, sin embargo, se quejaba de padecer un tiempo insoportable en Madrid, tanto de día como de noche, pues después de aver llovido aquí con suma abundancia largo tiempo, nevó un día, i unos quantos ha que yela fuertíssimamente ${ }^{56}$. No mejoraron las cosas con la entrada del nuevo año. Las precipitaciones, copiosas y seguidas, provocaron inundaciones, destruyeron puentes y, como era habitual, las comunicaciones postales quedaron interrumpidas. A finales de enero de 1758 de nuevo se lamentaba el bibliotecario de que no podía escribir porque le dolía muchísimo la muñeca, achacando tal cosa al hecho de que aquí nieva que es un contento, yela i hace un frío fuerte. La percepción que de ese invierno tuvo Martínez Pingarrón dibuja, con la precisión de un periodista, las tribulaciones que afrontaron quienes residían en la Corte y, por extensión, en muchos lugares de la España interior. Anotaba el presbítero el día 4 de febrero:

«Aquí hemos tenido (i aún tenemos) un invierno de los más crueles que pueden experimentarse. Hoi hace quince días que cayó una grandíssima nevada, heló después i aún estamos cubiertos de nieve i yelo. Son muchas las desgracias que han suce(di)do en personas i cavallerías; todo Madrid está hecho una loncha de yelo, aunque tomaron la providencia de echar estiercol por las calles. Ha muerto mucha gente ${ }^{57}$.

\footnotetext{
54 Mayans a Martínez Pingarrón, Oliva, 8-1-1757, pp. 64-65; cf. MAYANS, 1988, pp. 64-65.

55 Mayans a Martínez Pingarrón, Oliva, 23-7-1757; cf. MAYANS, 1988, pp. 97-98.

56 Martínez Pingarrón a Mayans, Madrid, 24-12-1757; cf. MAYANS, 1988, p. 115.

57 Martínez Pingarrón a Mayans, Madrid, 4-2-1758; cf. MAYANS, 1988, p. 118. Las cursivas son mías.
} 
El epistolario carece de pormenores climáticos referidos tanto al estío como al invierno de 1758, aunque abundan los relativos al fallecimiento de la reina, Bárbara de Braganza, y a su polémica disposición testamentaria, así como al lamentable estado de salud de Fernando VI, que moriría el 10 de agosto, y a la honda preocupación que todo ello causaba en ministros y magistrados. Ese verano de 1759 fue muy riguroso, con proliferación de enfermedades, sequía y calores extraordinarios a duras penas interrumpidos por algún chaparrón a comienzos de septiembre. De todo ello dio cuenta Martínez Pingarrón a Mayans junto con la noticia de la proclamación de Carlos III como rey de España, de las previsiones de su viaje desde Nápoles y de cómo numerosos cortesanos comenzaban a partir hacia Barcelona para preparar la bienvenida a los nuevos soberanos.

A primeros de diciembre, Pingarrón preveía un invierno tan duro como los anteriores. Escribía, con amargura y justificando la cortedad de su misiva, que el tiempo era cruel porque el ayre es grande $i$ sumamente frío; me ha destemplado la cabeza i tengo una fluxión a un ojo que me levanta. Por eso no soy más largo (MAYANS, 1987, p. 174). Por esas fechas, el estado del tiempo era motivo de general preocupación pues Carlos III y su esposa acababan de salir de Zaragoza dos días antes y tenían previsto llegar a Madrid el 7 de diciembre. La inestabilidad atmosférica desbarató los planes, y el mal temporal retrasó un tanto la entrada en Madrid de la comitiva real que padeció fuertes aguaceros después de aver nevado i hecho crueles fríos, ocasionados de un ayre penetrantíssimo ${ }^{58}$. Pese a las adversidades meteorológicas la demora no representó más allá de dos días, y en la tarde del domingo 9 los madrileños recibieron efusivamente a la familia real. Martínez Pingarrón, en carta remitida a Mayans seis días más tarde, dedica largos párrafos a efectuar una primera valoración acerca del carácter y aptitudes del nuevo monarca así como de las expectativas y temores que levantaba entre la clase política, anotando que aunque el tiempo, precisamente, no acompañaba fue sin igual el regocijo de las gentes pues, aunque llovía a mares (como lo hace más ha de quince días) salieron al camino inumerables almas ${ }^{59}$.

Como es de ver, la década de los cincuenta de la centuria ilustrada no resultó buena en España. Los indicadores económicos y demográficos apuntan en esa dirección. En los años 1750-1751 y 1753-1754 los precios del trigo alcanzaron máximos significativos en las dos Castillas y en Andalucía, tendiéndose a considerar la crisis de subsistencias padecida en 1753 como una de las más violentas de la centuria anunciadora de un inmediato cambio de coyuntura motivado por la súbita disminución de las cosechas, la brutal subida de los precios y el incremento de las rentas de la tierra ante la gran demanda existente (ANES, 1970, pp. 209-215, 399, 429-430). La sequía y la prolongada plaga de langosta que azotó los campos de buena parte del país entre 1756 y 1758 contribuyeron a endurecer, aún más si cabe, la situación. La explosión violenta de los campesinos, ejemplificada en los motines de mediados de los sesenta, estaba, pues, a la vuelta de la esquina. Con las condiciones climáticas interpretando, una vez más, su papel.

\section{Bibliografía citada}

ABASCAL, J. M.; DIE, R. y CEBRIÁN, R. (2009): Antonio Valcárcel y Pío de Saboya, conde de Lumiares (1748-1808). Apuntes biográficos y escritos inéditos. Real Academia de la HistoriaInstituto de Cultura «Juan Gil-Albert», Madrid-Alicante.

ALBEROLA ROMÁ, A. (1985): «Una enfermedad endémica en el Alicante del XVIII: las fiebres tercianas», en Revista de Historia Moderna, ${ }^{\circ}$ 5, pp. 127-140.

58 Martínez Pingarrón a Mayans, Madrid, 8-12-1759; cf. MAYANS, 1988, pp. 174-175.
59 Martínez Pingarrón a Mayans, Madrid, 15-12-1759; cf. MAYANS, 1988, pp. 175-177. 
ALBEROLA ROMÁ, A. (1999): Catástrofe, economía y acción política en la Valencia del siglo XVIII, Edicions Alfons el Magnánim. Valencia.

ALBEROLA ROMÁ, A. (2005): «El terremoto de Lisboa en el contexto del catastrofismo natural en la España de la primera mitad del siglo XVIII», en Cuadernos Dieciochistas, nº 6, pp. 19-42.

ALBEROLA ROMÁ, A. (2006): «Entre la sequía y la inundación. Una aproximación a las avenidas históricas de los ríos valencianos durante el siglo XVIII», en CHASTAGNARET, G. y GIL OLCINA, A. (Dirs.): Riesgo de inundaciones en el Mediterráneo occidental, Casa de VelázquezUniversidad de Alicante, Madrid, pp. 1-30.

ALBEROLA ROMÁ, A. (2009): «La natura desfermada. Al voltant de manuscrits, impresos i imatges sobre desastres naturals en l'Espanya del segle XVIII», en ALBEROLA, A. y OLCINA, J. (Eds.): Desastre natural, vida cotidiana y religiosidad popular en la España moderna y contemporánea, Publicaciones de la Universidad de Alicante, Alicante, pp. 17-76.

ALBEROLA ROMÁ, A. (2010): Quan la pluja no sap ploure. Sequeres i riuades al País Valencià en l'edat moderna, Publicacions de la Universitat de València, València.

ALBEROLA ROMÁ, A. y BERNABÉ GIL, D. (1998-1999): «Tercianas y calenturas en tierras meridionales valencianas: una aproximación a la realidad médica y social del siglo XVIII», en Revista de Historia Moderna, $\mathrm{n}^{\circ}$ 17, pp. 95-112.

ANES, G. (1970): Las crisis agrarias en la España moderna. Taurus, Madrid.

BACALLAR DE SANNA, V., marqués de San Felipe (1957): Comentarios de la guerra de España e historia de su Rey Felipe V, el Animoso. Memorias políticas y militares. Tratados de paz y alianzas de España. ¿Génova, 1726?, edición y Estudio Preliminar de Carlos Seco Serrano, B.A.E., Madrid.

BARRIENDOS, M. (1999): «La climatología histórica en el marco geográfico de la antigua monarquía hispana», en Scripta Nova. Revista Electrónica de Geografía y Ciencias Sociales, n ${ }^{\circ}$ 53, 1 de diciembre de 1999. Universidad de Barcelona [ISSN 1138-9788].

BARRIENDOS, M. y LLASAT, C. (2009): «El caso de la anomalía <Maldá> en la cuenca mediterránea occidental (1760-1780). Un ejemplo de fuerte variabilidad climática», en ALBEROLA, A. y OLCINA, J. (Eds.): Desastre natural, vida cotidiana y religiosidad popular en la España moderna y contemporánea, Publicaciones de la Universidad de Alicante, Alicante, pp. 253-286.

BORDAZAR DE ARTAZU, A. (1731): Puntual relación de la Avenida de el Río Turia, que baña à esta ciudad de Valencia, sucedida el dia 16 de Setiembre de 1731, en Valencia, con las licencias necesarias por Antonio Bordazar, s.f., 8 páginas.

BUFFON, conde de (1797): Historia natural, general y particular escrita en francés por --- (...), traducida por D. Joseph Clavijo y Fajardo, Director del Real Gabinete de Historia Natural (...). Madrid, por la viuda de don Joaquín Ibarra, tomo VI, segunda edición, MDCCXCVII.

CEBRIÁN FERNÁNDEZ, R., SALAMANQUÉS PÉREZ, V., SÁNCHEZ MEDINA, E. (2005): «La documentación sobre las Memorias del viaje del marqués de Valdeflores por España (Real Academia de la Historia, Ms. 9/7018)», en SPAL (Universidad de Sevilla), no 14, pp. 11-57.

DIE MACULET, R. y ALBEROLA ROMÁ, A. (2010): «José Carbonel Fougasse (1707-1801). Un erudito en la España ilustrada», en Revista de Historia Moderna, $\mathrm{n}^{\circ} 28$.

FAUS PRIETO, F. (1988): «Aspectos geográficos en la obra de Antonio Bordazar de Artazu, impresor erudito valenciano del siglo XviII», en Cuadernos de Geografía, núm. 43, pp. 1-22.

FEIJOO, B. J. (1786): Cartas eruditas, y curiosas, en que, por la mayor parte se continua el designio del Teatro critico universal, impugnando, ó reduciendo á dudosas varias opiniones comunes, Pamplona. En la Imprenta de Benito Cosculluela, 1786, Tomo I.

FONT TULLOT, I. (1988): Historia del clima en España. Cambios climáticos y sus causas, Madrid.

GIMÉNEZ LÓPEZ, E. (1981): «La acción política del humanista Felipe Bolifón», en Mayans y la Ilustración. Simposio Internacional en el Bicentenario de la muerte de Gregorio Mayans, Publicaciones del Ayuntamiento de Oliva, Valencia, Tomo II, pp. 613-627.

GIMÉNEZ LÓPEZ, E. (2001): «El primer capitán general de Cataluña, marqués de Castelrodrigo (1715-1621) y el control del austracismo», en FERNÁNDEZ ALBALADEJO, P. (Ed.): Los Borbones. Dinastía y memoria de nación en la España del siglo XVIII, Madrid, pp. 401-420.

KAMEN, H. (1974): La Guerra de Sucesión en España, 1700-1715, Barcelona. 
LE ROY LADURIE, E. (1991): Historia del clima desde el año mil, México.

LE ROY LADURIE, E. (2004): Histoire humaine et comparée du climat. Canicules et glaciers, XIII-XVIIIe siècles, Fayard, Paris.

LUCENA GIRALDO, M. (1992): Laboratorio tropical. La expedición de límites al Orinoco, 17501767. Monte Ávila Editores-CSIC. Caracas.

MAIER, J. (2002): Comisión de Antigüedades de la Real Academia de la Historia. Documentación general. Catálogo e índices. Madrid.

MALTÉS, J. B. y LOPPEZ, L. (1752): Ilice Ilustrada. Historia de la muy noble, leal y fidelísima ciudad de Alicante, Década VII, epígrafes 141, 156 y 157. Copia manuscrita de 1889 del original de 1752 conservada en el Archivo Municipal de Alicante. Se imprimió en 1907, en la Tipografía El Progreso, con el título de Ilice Ilustrada. Historia de las antigüedades, grandezas y prerrogativas de la muy noble y siempre leal ciudad de Alicante. Hay edición facsímil de la copia manuscrita, con un estudio preliminar de A. Alberola y C. Mas, publicada por el Ayuntamiento de Alicante en 1991 dentro de su colección Fuentes Históricas de Alicante.

MARTÍ ESCAYOL, M. a A. (2009): ««Esto advartesch per la espariencia dels qui vindran». Dietaris, percepció de desastre i gestió de risc natural», en ALBEROLA, A. y OLCINA, J. (Eds.) (2009): Desastre natural, vida cotidiana y religiosidad popular en la España moderna y contemporánea, Publicaciones de la Universidad de Alicante, Alicante, 2009, pp. 77-129.

MARTÍNEZ SOLARES, J. M. (2001): Los efectos en España del terremoto de Lisboa (1 de noviembre de 1755). Transcripción documental de Fernando Rodríguez de la Torre. Ministerio de Fomento, Madrid.

MAYANS Y SISCAR, G. (1973): Epistolario III. Mayans y Martí. Transcripción, notas y estudio preliminar de A. Mestre, Publicaciones del Ayuntamiento de Oliva, Valencia.

MAYANS Y SISCAR, G. (1987): Epistolario VII. Mayans y Martínez Pingarrón, 1. Historia cultural de la Real Biblioteca. Transcripción, notas y estudio preliminar de A. Mestre, Publicaciones del Ayuntamiento de Oliva, Valencia.

MAYANS Y SISCAR, G. (1988): Epistolario VIII. Mayans y Martínez Pingarrón, 2. Los manteístas y la cultura ilustrada. Transcripción, notas y estudio preliminar de Antonio Mestre. Publicaciones del Ayuntamiento de Oliva, Valencia.

MAYANS Y SISCAR, G. (1991): Epistolario XIII. Mayans y Jover. 1. Un magistrado regalista en el reinado de Felipe $V$. Transcripción, notas y estudio preliminar de P. Molas. Publicaciones del Ayuntamiento de Oliva. Valencia.

MAYANS Y SISCAR, G. (1993): Epistolario XII. Mayans y los libreros. Transcripción, notas y estudio preliminar de Antonio Mestre. Publicaciones del Ayuntamiento de Oliva, Valencia.

MAYANS Y SISCAR, G. (1995): Epistolario XIII. Mayans y Jover. 2. Un magistrado regalista en el reinado de Felipe $V$. Transcripción, notas y estudio preliminar de Pere Molas. Publicaciones del Ayuntamiento de Oliva. Valencia.

MAYANS Y SISCAR, G. (1996): Epistolario XIV. Mayans y los altos cargos de la magistratura y administración borbónica. 1 (1716-1750). Edición y estudio preliminar de A. Mestre y P. Pérez García, Publicaciones del Ayuntamiento de Oliva. Valencia.

MESTRE SANCHIS, A. (1968): Ilustración y reforma de la Iglesia. Pensamiento político-religioso de don Gregorio Mayans y Siscar (1699-1781), Publicaciones del Ayuntamiento de Oliva, Valencia.

MESTRE SANCHIS, A. (1970): Historia, fueros y actitudes políticas. Mayans y la historiografía del XVIII, Publicaciones del Ayuntamiento de Oliva, Valencia.

MESTRE SANCHIS, A. (1999): Don Gregorio Myans y Siscar. Entre la erudición y la política, Institució Alfons el Magnànim, València.

MESTRE SANCHIS, A. (2000): «La carta, fuente de conocimiento histórico», en Revista de Historia Moderna, n $^{\circ}$ 18, pp. 13-26.

MESTRE SANCHIS, A. (2003): Manuel Martí, el Deán de Alicante, Instituto de Cultura «Juan Gil-Albert», Alicante.

ORLOVE, B. y STRAUSS, S. (Eds.) (2003): Weather, culture, climate. Berg, London.

PALOP RAMOS, J. M. (1977a): Fluctuaciones de precios y abastecimiento en la Valencia del siglo XVIII. Ed. Alfonso el Magnánimo, Valencia. 
PALOP RAMOS, J. M. (1977b): Hambre y lucha antifeudal. Las crisis de subsistencia en Valencia (siglo XVIII), Ed. Siglo XXI, Madrid.

PELAYO LÓPEZ, F. (Ed.) (1990): Pehr Löfling y la expedición al Orinoco (1754-1761), Turner, Madrid.

PÉREZ DURÁ, J. (1979): Epistolario Manuel Martí, deán de Alicante, y Felipe Bolifón, Instituto de Estudios Alicantinos, Alicante.

PÉREZ MARTÍNEZ, T. y FAUS PRIETO, A. (1990): «La inundación del Turia de 1731. Narración histórica e interpretación geográfica», Quaderns d'Investigació d'Alaquás, IX, pp. 15-29.

PÉREZ MOREDA, V. (1980): Las crisis de mortalidad en la España interior (siglos XVI-XIX), Siglo XXI, Madrid.

RICO SINOBAS, M. (1851): Memoria sobre las causas meteorológico-físicas que producen las constantes sequías de Murcia y Almería, señalando los medios para atenuar sus efectos. Imprenta de D. S. Compagni, Madrid.

RICO SINOBAS, M. (1858): Estudios meteorológicos y topográficos-médicos en España en el siglo XVIII, Madrid, $17 \mathrm{pp}$.

SÁEZ VIDAL, J. (1985): La ciudad de Alicante y las formas artísticas de la cultura barroca: 1691 1770 , Instituto de Estudios «Juan Gil-Albert», Alicante.

SAINT-SIMON, Louis de Rouvroy, duque de (1983-1988): Mémoires: additions au Journal de Dangeau, Gallimard, Paris, 8 vols.

SALVÁ, M. y SAINZ DE BARANDA, P. (1848): «Correspondencia que tuvo el jesuita Andrés Marcos Burriel con varias personas sobre la Comisión que le dio el Gobierno de examinar los archivos de Toledo, junto con otros papeles en que se da noticia de igual examen de diferentes archivos del reino (Archivo de mss. de la Academia de la Historia», en Colección de documentos inéditos para la Historia de España, Madrid, imprenta de la viuda de Calero, tomo XIII.

VARGAS PONCE, J. (1808): Varones ilustres de la Marina española. Vida de D. Juan Josef Navarro, primer marqués de la Victoria, por el Capitán de Fragata D. ---, Madrid, en la Imprenta Real.

VELÁZQUEZ, L. J., marqués de Valdeflores (1765): Noticia del viage de España hecho por orden del Rey. Y de una nueva Historia General de la Nacion desde el tiempo mas remoto hasta el año de 1516. Sacada unicamente de los Escritores y Monumentos originales, y contemporaneos (...). Por D. Luis Josef Velazquez de Velasco, Marqués y Señor de Valdeflores, Señor de Sierra blanca, Caballero de la Orden de Santiago. En Madrid. En la Oficina de D. Gabriel Ramirez. Año de 1765.

VERGADÁ, P. (1731): Verdadero Resumen y compendioso diseño de la memorable avenida de el Turia, principal rio de Valencia: reflujo de sus barrancos, y estragos de sus efectos; en el dia 16 de Setiembre de este presente año 1731.15 páginas. 